Article

\title{
Static Geological Modelling with Knowledge Driven Methodology
}

\author{
Jun $\mathrm{Li}^{1}{ }^{1} *$, Xiaoying Zhang ${ }^{2}$, Bin $\mathrm{Lu}^{2}$, Raheel Ahmed ${ }^{2}$ and Qian Zhang ${ }^{1}$ \\ 1 State Key Laboratory of Geomechanics and Geotechnical Engineering, Institute of Rock and Soil Mechanics, \\ Chinese Academy of Sciences, Wuhan 430071, China; zhangqian1205cn@126.com \\ 2 Dimue Technology, Ltd. Co., Wuhan 430000, China; jane.zhang@dimue.com (X.Z.); \\ robin.lu@dimue.com (B.L.); raheel.ahmed@dimue.com (R.A.) \\ * Correspondence: lijun@whrsm.ac.cn or lijun2009s@gmail.com
}

Received: 20 August 2019; Accepted: 6 October 2019; Published: 8 October 2019

check for updates

\begin{abstract}
Geological modelling is an important topic of oil and gas exploration and production. A new knowledge driven methodology of geological modelling is proposed to address the problem of "hard data" limitation and modelling efficiency of the conventional data driven methodology. Accordingly, a new geological modelling software (DMatlas) (V1.0, Dimue, Wuhan, China) has been developed adopting a grid-free, object-based methodology. Conceptual facies models can be created for various depositional environments (such as fluvial, delta and carbonates). The models can be built largely based on geologists' understandings with "soft data" such as outcrops analysis and geological maps from public literatures. Basic structures (fault, folds, and discrete fracture network) can be easily constructed according to their main features. In this methodology, models can be shared and re-used by other modelers or projects. Large number of model templates help to improve the modelling work efficiency. To demonstrate the tool, two case studies of geological modelling with knowledge driven methodology are introduced: (1) Suizhong 36-1 field which is a delta depositional environment in Bohai basin, China; (2) a site of the north Oman fracture system. The case studies show the efficiency and reliability within the new methodology.
\end{abstract}

Keywords: geological modelling; knowledge-driven methodology; depositional environments; structure; oil and gas exploration and production

\section{Introduction}

Geological modelling, in terms of structure, sedimentological facies and petrophysical properties is an essential way to quantitative understanding of the underground information. The main aim is to enhance the reliability of decision-making for underground natural resource evaluation and recovery [1]. Geological modelling plays an important role for the work flow of the gas/oil exploration and production. It provides fundamental geological structures, sand body distributions, and petrophysical properties simulation. Reserve volume calculation and dynamic reservoir simulation can be carried out based on the models.

Data is the basis in the work flow of geological modelling. The data is in terms of seismic interpretation, well logs/cores and their derived interpretations, analog/outcrop, etc. [2]. In conventional way of geological modelling (such as Petrel modelling [3]), a lattice with a largely deterministic structural and stratigraphic framework is constructed to begin with seismic interpretation such as fault sticks and surfaces. Well tops, isochores or zone logs are used to insert stratigraphic horizons and zones within a reservoir. A grid then is in place with layers varying in thickness. Facies or rock type is populated to each grid cell using geostatistical methods. Associated petrophysical properties determined from core- or log-derived data are assigned within the modelling facies. In the whole 
procedure of the conventional geological modelling methodology, mainly "hard data" (such as seismic data and well logs) is used to construct a geological model.

However, on one hand, there is limited "hard data" available for fields in the early stage of recovery. One the other hand, for $\mathrm{CO}_{2}$ geological storage projects, usually very limited number of wells are drilled, while the understanding of heterogeneity in inter-well scale is crucial for injection/production scheme design for EOR projects. [4] It is hard to build a reasonable geological model under both situations using conventional modelling method. Nevertheless, the lack of "hard data" does not mean that we know nothing about the reservoir geology or we can do nothing for geological modelling. In most cases, there is "soft data" like outcrops, geology interpretation images, and map contours. With the support of "soft data", geologists can bring forward limited possible scenarios of a reservoir in terms of structure, facies distribution and petrophysical properties. The concluded scenarios from "soft data" should also be modelled in computers to help geologists or reservoir engineer to carry out further analysis. Sech et al. [5] created three-dimensional geological model of a shoreface-shelf para-sequence reservoir analog from outcrops with surface-based modelling method.

For the "hard data" driven geological modelling methodology, tectonics and facies layout are all from seismic and well log data. Since subsurface geology is of high uncertainty, it is hard to fully capture the reservoir properties. The loss of some key information in "hard data" may trigger the violation of main geological principles in the geological model. It is hard for a geologist to correct the model according to his/her own knowledge in the context of "hard data" driven geological modelling methodology. Deveugle et al. [6] compared different statistic techniques of modelling to match a predefined reference model of fluvial-dominated deltaic reservoir. The study concludes that with specific "hard data" no statistical techniques can match the reference model, and interpreted geologic scenarios influence the dynamic fluid flow behavior more than statistic method selection. Conceptual models from geologists' knowledge or "soft data" should play an important role to help build a reasonable/useful geological model.

In addition, even though various realizations can be generated with different statistic techniques with "hard data" driven methodology [7], the software are usually non-intuitive and require modelers with strong knowledge of computer and statistics. Training cost is high since a series of demanding courses is needed to achieve skillful level. Also, the modelling procedure itself is time consuming and targeted revision afterwards usually requires tremendous endeavor with no ideal results.

Knowledge-driven approach for geological modeling has been applied to build models that can be shared by various potential users, possibly extended, updated, revised, or rebuilt in view of additional geological data or according to new geological interpretations [8]. Perrin et al. create a definite model by a history of various successive events [8]. The resulting arrangements of geologic objects, or various geological surfaces define a particular chrono-spatial structure of geological models. This paper proposes the knowledge-driven approach as a grid-free, object-based modeling method which is to store all the geo-objects and geologic sequences in the model without mapping them into a gridded system. The visual objects are represented with mathematical functions and not as sets of pixels as in raster graphics [9]. This type of facies modeling is not to model how and when the different facies bodies were deposited, but rather where the different facies bodies are present today. A new geological modelling tool named DMatlas is presented with "soft data" or knowledge driven methodology to substitute some undesirable procedures of conventional modeling workflow. The main properties of DMatlas include: (1) It is based on the knowledge driven modelling instead of "hard data" driven methodology; (2) conceptual models can be created by modelers with limited data; (3) with intuitive user interface, modelers can rapidly create multiple equally possible models to cover the uncertainties of a target reservoir; (4) large number of conceptual model templates are stored in a model library, based on which modelers can create their own model to improve the modelling efficiency; and (5) models can be shared and reused. 


\section{Knowledge Driven Methodology}

For the knowledge driven methodology, the most important input to build a reasonable model is the geologic understanding of the modeler (geologist). The more geologic knowledge of the target reservoir is, the better the geological model is for the target reservoir. DMatlas provides a platform from which modelers can create 3D conceptual models from the 2D sketches with their understandings of the target reservoir in terms of depositional environment, diagenesis and tectonic evolution. All models are shared in the DMatlas model library. When modelers create their models, one recommended operation at the very beginning is to search within similar models with keywords. They can select the closest matching model and customize it according to the specific conditions.

\subsection{Modelling Basis: Understanding from Perspective of Geologists}

To build a good geological model using DMatlas, a geologist should be conclusive of the possible scenarios of tectonic evolution, reservoir architectures, depths, facies distributions, and porosity and permeability distributions. Without possible scenarios in mind, one cannot build any model. The knowledge about the target reservoir can be obtained from seismic interpretation, outcrop analog, wells correlation, geological maps, public literature descriptions, etc. With the knowledge of target reservoir, the modeler can create all possible models on a computer by free hand drawing and editing, or template modifications. Hard data such as well logs can also be imported to condition the results accordingly. The adjustments can be for depth, facies distribution and structure. DMatlas modelling can be summarized as "basic modelling by free hand and adjustment by data". The fundamental basis is the modeler's knowledge about the target reservoir.

\section{2. $2 D$ Sketch for $3 D$ Facies Models}

DMatlas provides a platform using which geologists can create their own models intuitively including depositional facies and structures (such as faults, folds, and fractures).

In the real geological world, depositional environments fall into the following categories: alluvial, fluvial, lacustrine, delta, shallow marine, and deep sea. Each environment has its own unique sand body geometries. In plane geometry, the sand bodies can be belt (such as channel, river bed, and barrier island), sheet (such as distal bar, tidal flat and offshore sand), and fan-like, among others. With DMatlas, modelers can create 3D sand-bodies in a 2D interface for different sand body geometries.

\subsubsection{Modelling Algorithm}

There are mainly two 3D modeling methods used by DMatlas, namely lofting and Boolean operations [10]. Lofting is the procedure that takes a set of closed curves lying in parallel planes (Figure 1a) that are joined together to form a surface [11]. These curves are automatically linked with edges and facets to form the solid surface (Figure 1b). Lofting can also be realized using a path and closed curves, which means distributing one or multiple closed curves along the path in different positions. Figure 2 shows the front view of a lenticular sandbody modeled by DMatlas (Figure 2a) and its corresponding wireframe mode (Figure 2b).

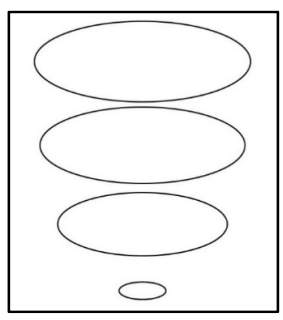

(a)

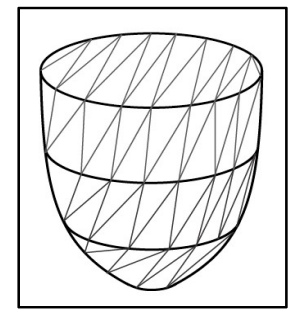

(b)

Figure 1. Sketch map of the lofting process: (a) A set of closed surfaces; (b) the solid surface connecting closed surfaces by edges and facets. 


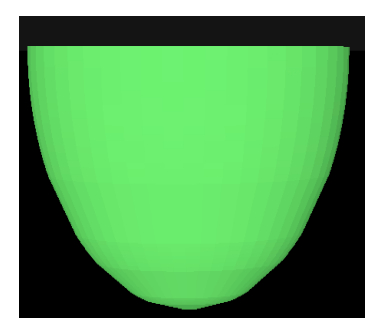

(a)

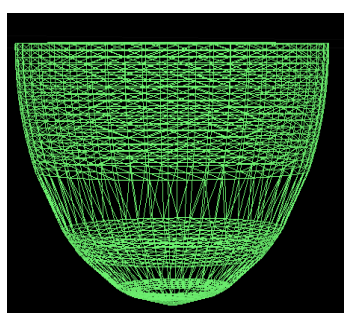

(b)

Figure 2. Front view of a lenticular sandbody and corresponding wireframe mode.

The other method is Boolean operation, which forms a new model via the summation, difference or intersection of multiple three-dimensional models [10] (Figure 3).

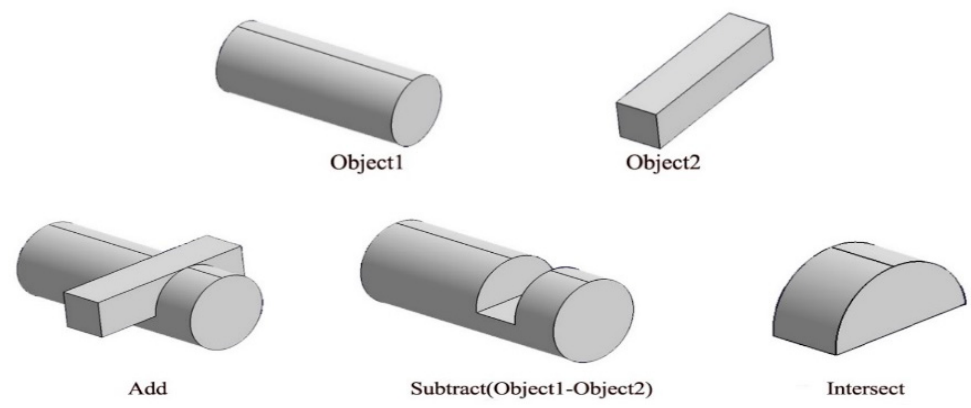

Figure 3. Sketch map of Boolean operations process.

\subsubsection{Belt Sand-Bodies}

The three-dimensional modelling of belt sand-bodies like a channel is achieved by lofting a section or sections along a path to stake out its shape. As modelers draw a sinuous trace representing a channel's plane distribution, extension and sinuosity on the 2D map view (Figure 4a), a default symmetrical parabolic shape (Figure $4 \mathrm{~b}$ ) is lofted along its center line (Figure 4c). When the height and width at a certain key point are modified, a different parabolic section is created at the same time. The 3D river channel is then reconstructed by lofting multiple sections along river center lines.

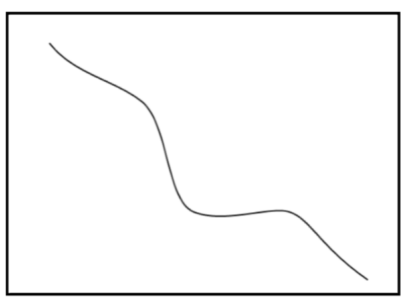

(a)

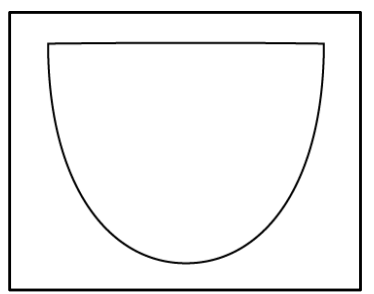

(b)

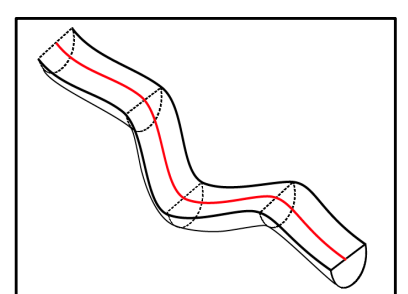

(c)

Figure 4. Sketch map of river channels modelling process: (a) Channel trace; (b) default parabolic cross-section shape; (c) perspective view of a simplified 3D channel highlighting the central line (red) and some cross-sections.

Figure 5 shows a 3D channel model (Figure 5c,d) generated from 2D sketching with key points of variable width and thickness (Figure 5a) by DMatlas, which are flagged as statistical average values from user-defined distribution. The default shape and dimensions of cross-sections are editable with all the key points selected (Figure 5b). 


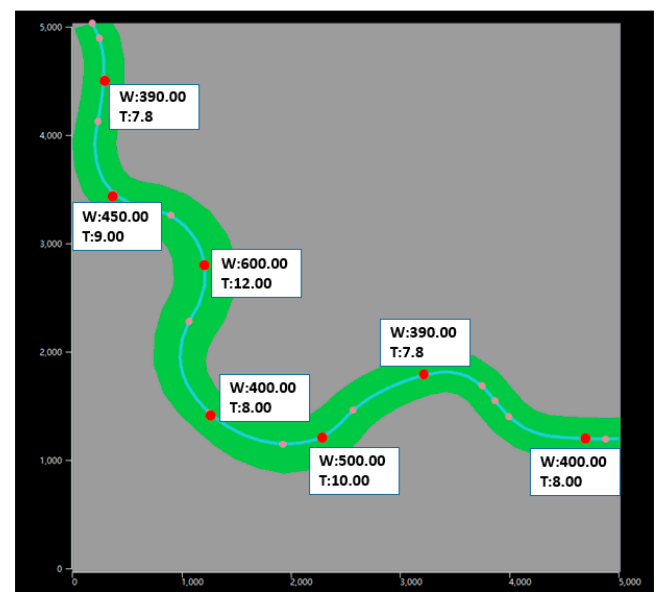

(a)

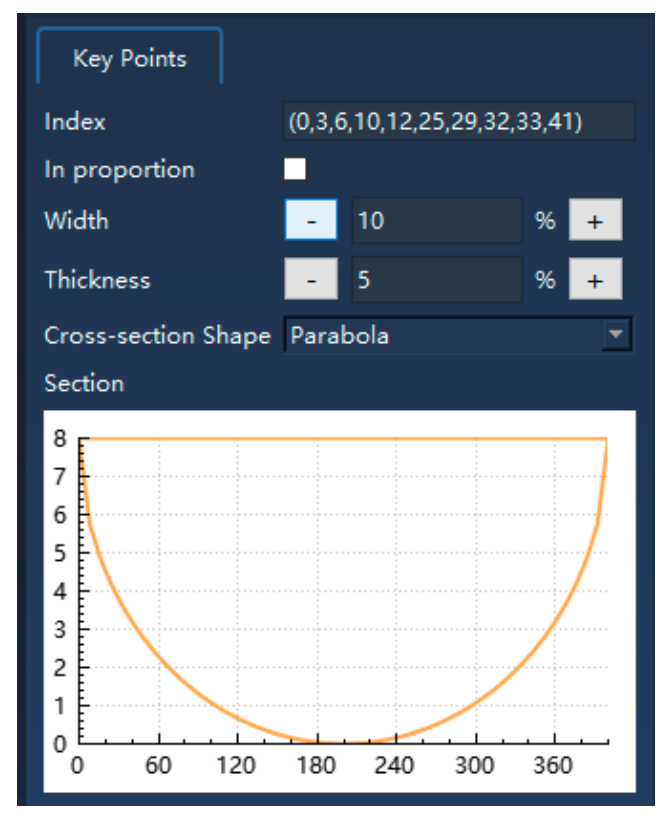

(b)

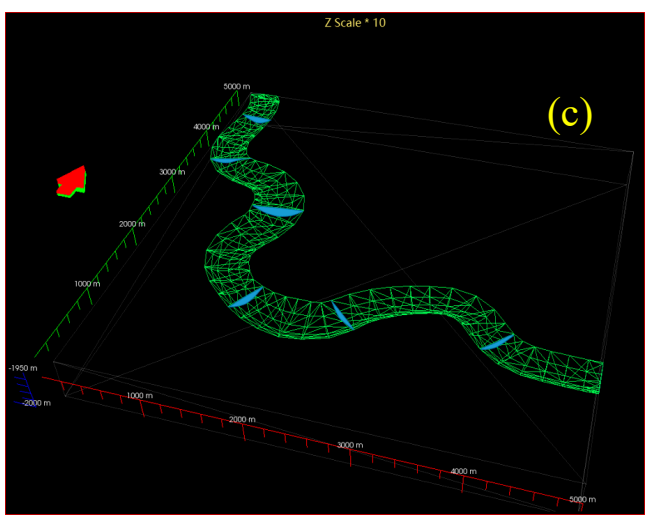

(c)

Figure 5. Cont. 


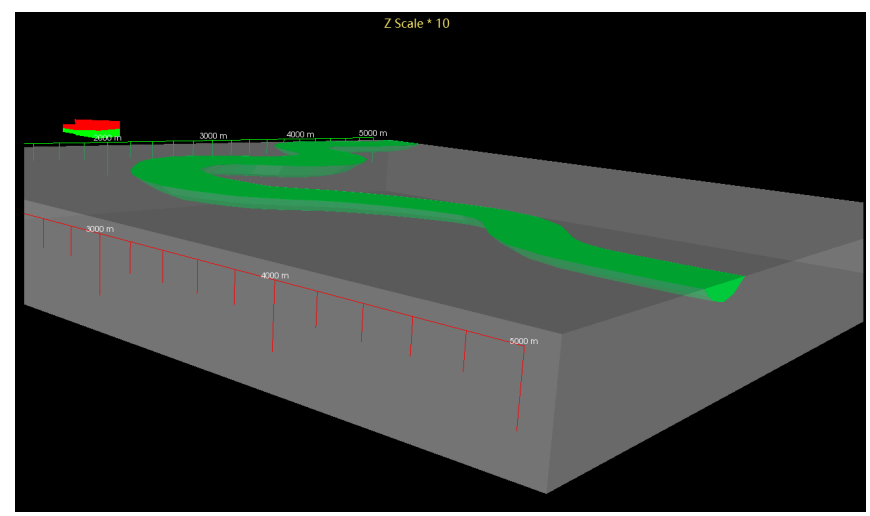

(d)

Figure 5. 3D channel model created from 2D sketch: (a) 2D editing mode showing different width $(\mathrm{W})$ and thickness (T) of different key points; (b) parameter setup panel of cross sections when all key points are selected; (c) 3D channel model in wireframe mode highlighting multiple cross-sections(blue); (d) oblique view of 3D channel model.

\subsubsection{Non-Belt Sand-Bodies}

Most sand-bodies in DMatlas are modeled via lofting multiple cross-sections and do not require a stake-out path. The maximum plane-view geometry of the sand-body is delineated first (Figure 6a), followed by designating the vertical cross-section shape. Figure 6b shows a convex-up lenticular shape. With maximum vertical thickness defined, multiple planar shapes scaled by cross-section shape are generated at different vertical positions (Figure 6c). Finally, a 3D sand-body is generated with these 2D planes lofted in the vertical direction.

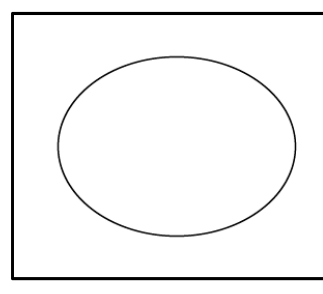

(a)

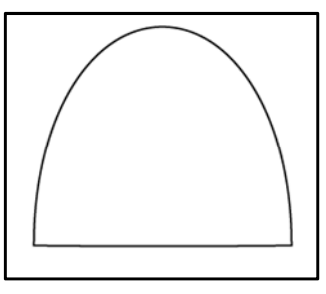

(b)

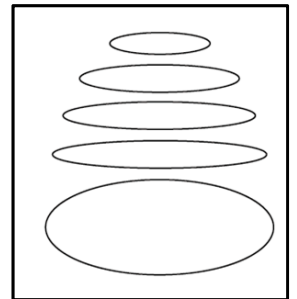

(c)

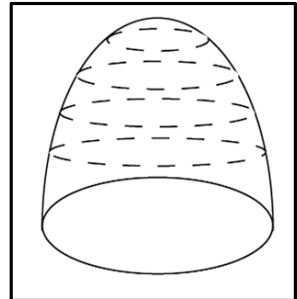

(d)

Figure 6. Sketch map of a lenticular sand-body modelling process: (a) 2D plane section geometry; (b) vertical cross-section of convex-up lenticular shape; (c) multiple planar surfaces; (d) 3D lenticular sand-body model.

The plane view of most architecture units can be sketched either by free-hand delineation or by editing available shape templates. Figure 7 shows these two ways of sketching plane-section geometry of river mouth bars in a delta environment.

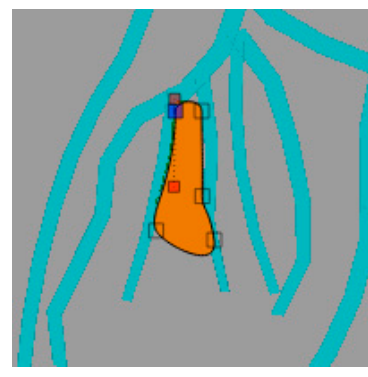

(a)

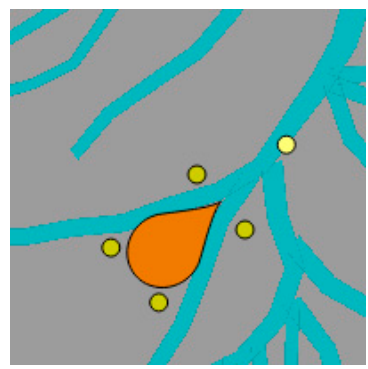

(b)

Figure 7. Free-hand delineation (a) and shape template editing (b) sketching plan view of sand-bodies. 
Cross-section shape and maximum thickness is to be set afterwards to loft plane geometry completing the construction of the 3D sand-bodies. Figure 8 shows the four vertical cross-section shapes provided by DMatlas: Tabular, wedge-shaped, lenticular shape of convex-up and concave-down.

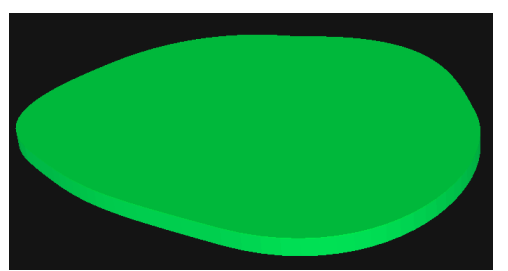

(a)

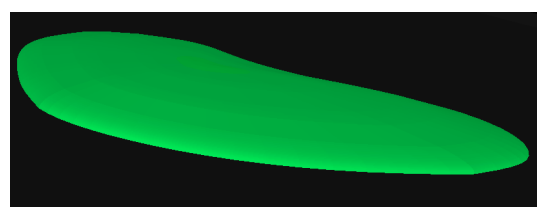

(c)

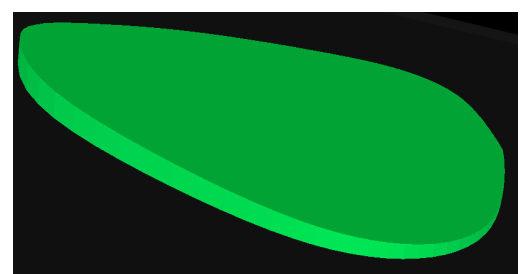

(b)

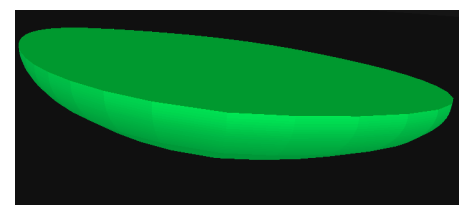

(d)

Figure 8. Sandbody models of four vertical cross-section types: (a) tabular; (b) wedge-shapes; (c) bottom flat convex; and (d) top flat convex.

\subsubsection{Carbonate Reefs}

In addition to the lofting method, the carbonate reefs also use the important 3D modeling method "Boolean operation". To model a knoll reef, an integral 3D reef shape (Figure 9a) is built first, followed by the construction of a cylinder (Figure 9b). Then the reef core (Figure 9d) is obtained with intersection of these two models (Figure 9c), and the difference between the 3D reef shape and reef core gets the reef flank (Figure 9e), together comprising a completed knoll reef (Figure 9f).

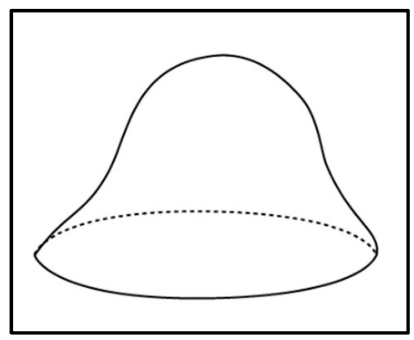

(a)

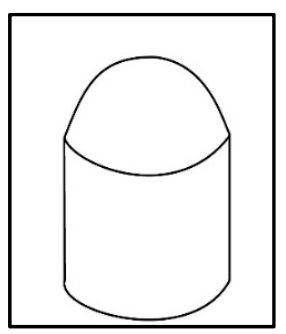

(d)

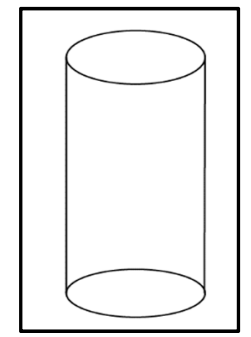

(b)

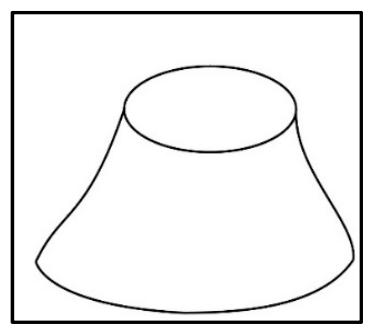

(e)

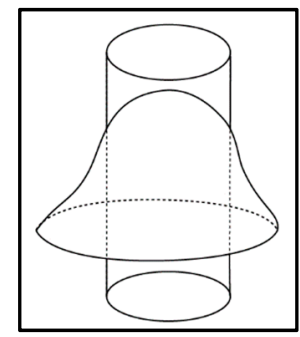

(c)

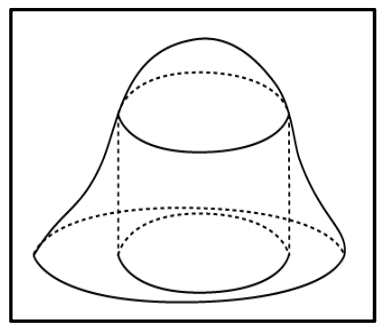

(f)

Figure 9. Key elements indicating the method of modeling a carbonate reef (knoll reef): (a) An integral reef; (b) a cylinder; (c) Boolean operation; (d) reef core; (e) reef flank; and (f) 3D knoll reef.

As to user interaction, both the geometry of top plane view (Figure 10a) and the maximum vertical cross-section (Figure 10b) are needed to be defined. By adjusting the locations of controlling points (yellow and red circles in Figure 10), a knoll reef is modelled in 3D as Figure 10c shows. 


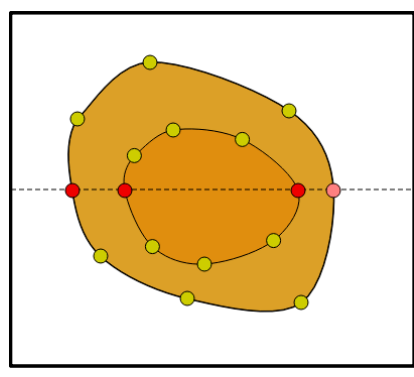

(a)

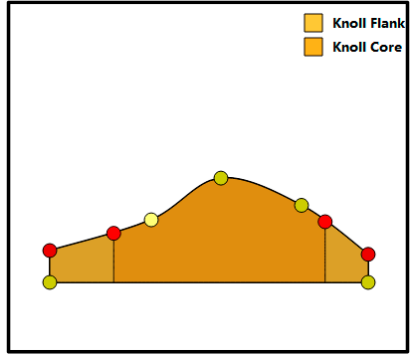

(b)

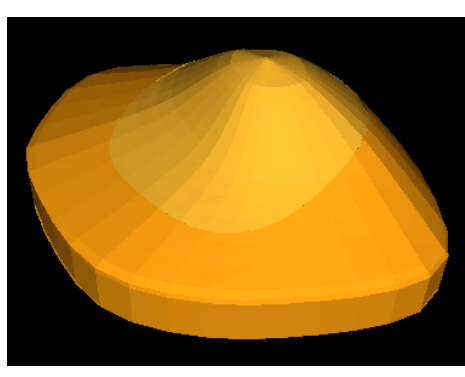

(c)

Figure 10. DMatlas interfaces constructing carbonate reef models: (a) Top view; (b) maximum cross-section view; and (c) 3D knoll reef model.

\subsection{Structure Modelling}

To model structures like fault, fold, and fractures by DMatlas, parameters that capture their major morphology features are input directly within 2D interface to simulate various tectonic results.

Figure 11 shows a general dip-slip fault modeling process. The model A (Figure 11a) is to be faulted by Fault B (Figure 11b). First, a model C (Figure 11c) is constructed according to user-input fault parameters. And then the model D is intersected via Boolean operation with model A and C. At last, model $\mathrm{E}$ is obtained with the Boolean difference operation between model $\mathrm{A}$ and $\mathrm{D}$, together with model D comprising a completed fault model (Figure 11d). All geological body models are divided into two parts after such an operation by one fault.

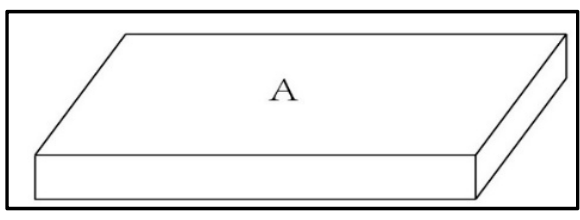

(a)

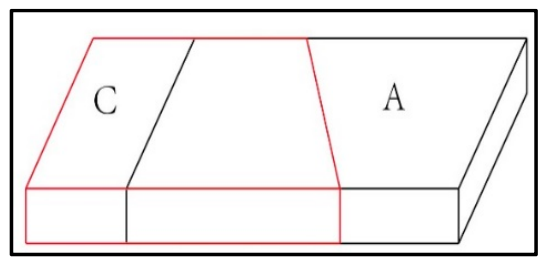

(c)

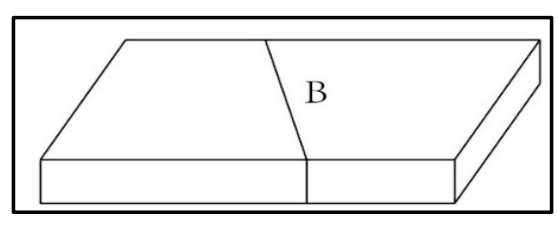

(b)

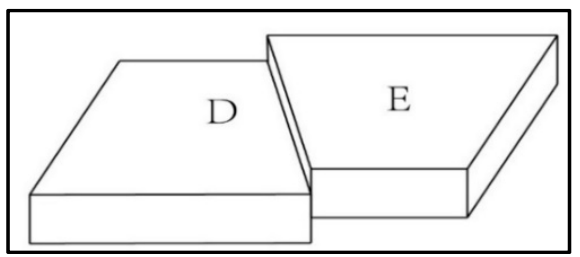

(d)

Figure 11. Sketch map illustrating faulting process in DMatlas.

The deformation modelling of fold and variable thickness is relatively simple. According to the parameter settings, each closed curve for lofting is correspondingly displaced, and re-staked to complete 3D modeling, realizing the folding and topographic relief. As for discrete fractures which are $2 \mathrm{D}$ surfaces, they are generated based on the user-input parameters, like orientation, length, and terminating surfaces.

\subsection{Model Library}

The 'model library' in DMatlas refers to the hundreds to thousands of models accumulated during the construction of conceptual models, case models and field models, out of study and research necessity, or real projects practice. The models in the library are sorted with their attributes such as depositional environments, field names, facies types, geological ages, and representative basins. Geologists can input keywords to search for models which closely match their target model(s). With customization of the model, modelers can rapidly create their own model. The modelling time is sufficiently reduced 
in this way. Figure 12 shows a fast-build fluvial model (Figure 12c) by importing, copying, shifting, rotating and (proportionably) changing thickness/with of channels and other sandbodies from two anastomosing (Figure 12a) and meandering (Figure 12b) models.

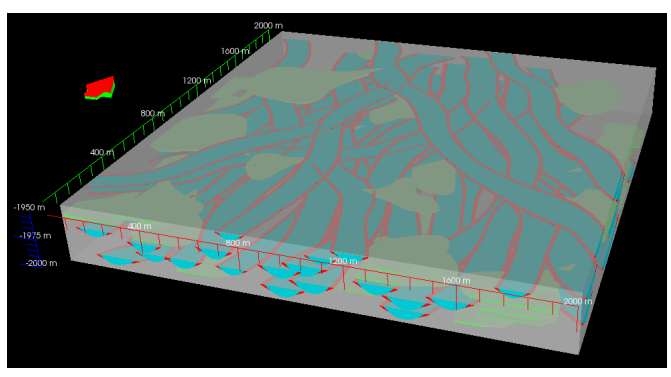

(a)

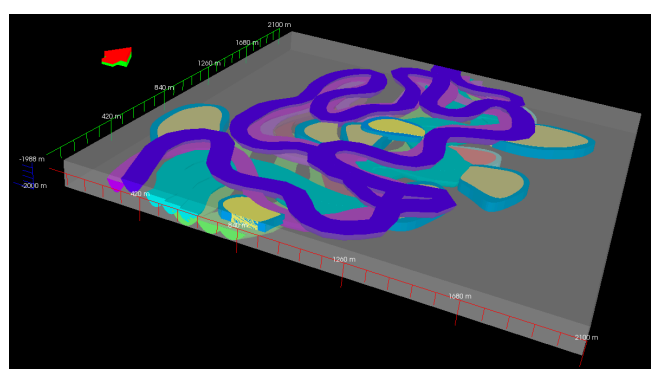

(b)

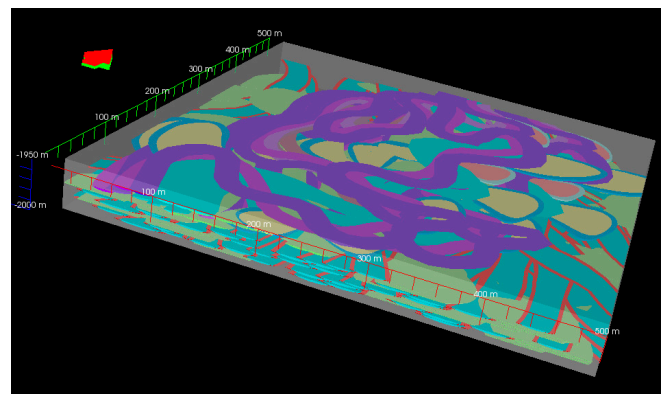

(c)

Figure 12. Construct a new model by customizing templates from model library. (a) an anastomosing river model template; (b) a meandering river model template; (c) a customized new model combing (a) and (b).

\section{Illustration of DMatlas Modelling Process}

We present a rapid and intuitive approach to model reservoir model concepts, which complements existing workflows and makes it possible to introduce both small-scale features and large-scale features. Reservoir architecture units, defined by 4th or 5th order bounding surfaces established by Miall [12] for fluvial depositional system, are modelled as discrete volumes enveloped by surfaces without reference to a predefined grid. In this section, a prototype of the DMatlas workflow is demonstrated using a number of examples.

The fundamental idea of DMatlas is to model where the different facies bodies are present today and prototype sedimentary concepts rapidly. Users model reservoirs in a guiding sequence of (1) sedimentology, (2) structure, and (3) petrophysical properties, which corresponds to five modules of DMatlas workflow (Figure 13) that include (1) Model, (2) Well, (3) Facies, (4) Structure, and (5) Property:

Model: Unlike conventional modelling which defines a grid importing well/seismic tops in the first place, DMatlas allows modelers to start with box-shaped zone (as one unit, layer or formation, depending on user definition) of uniform thickness, enabling geologists to rapidly test sedimentary concepts and scenarios. Modelers could refer to structure maps to define a zone's top or base depth, considering subsequent deformation like variable thickness, fault and etc.

Facies modelling: The idea of DMatlas facies modelling is similar to object-based modelling or sketch-based modelling. DMatlas provides various types of sand-bodies, like belt-shaped channels, lenticular sandbars, and top-convex reefs which are generated based on some geologic rules and stored in a grid-free format. Modelers decide which object is required for the current step of modeling and set sand-bodies directly to their location and depth based on sedimentological study.

Structure modelling: With facies in-situ, modelers can move on to the structure module to restore tectonic effects on the facies. Variable thickness, Fold, Fault, and DFN (Discrete fracture network) 
are available. Functionalities like Variable thickness are often non-tectonic related, but are reflections of zone deformation.

Property modelling: Modelers can carry on grid building and petrophysical properties population by assigning stochastic distribution function based on statistics and interpretation.

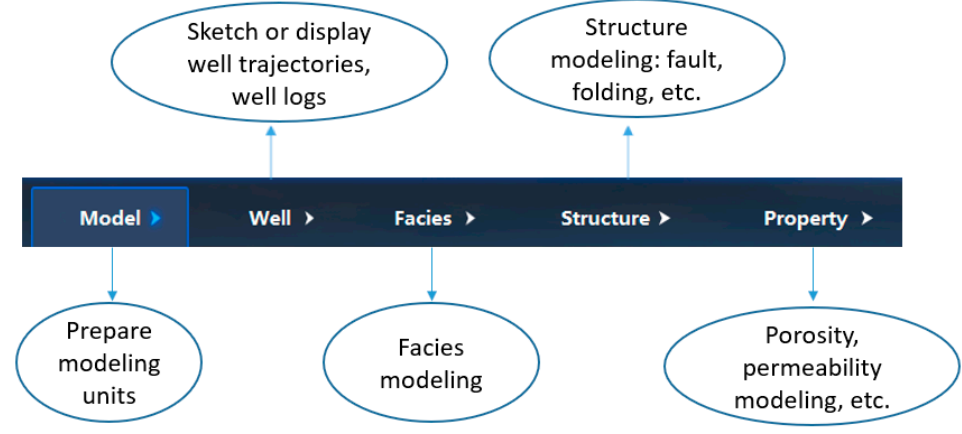

Figure 13. Frame diagram indicating five main modules and workflow of DMatlas.

\subsection{Fluvial Environment}

In fluvial environments, following types of facies are included: valley, channel, levee, point bar, bars, crevasse splay, overbank deposit and oxbow lake (Figures 14 and 15). Channels and valleys are modeled with the method described in Section 2.2.1 (belt type sand-bodies). The rest facies can be created following the method in Section 2.2.2 (non-belt sand-bodies).

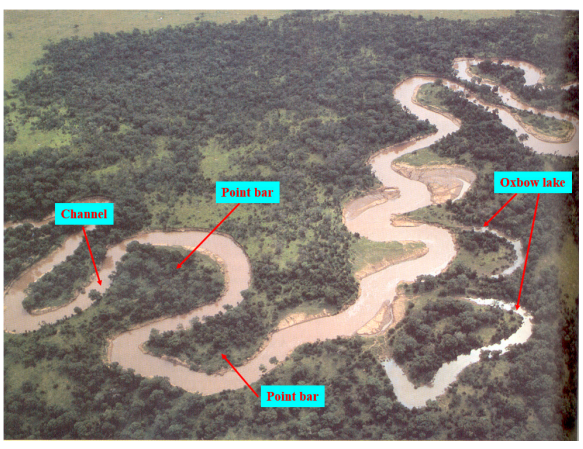

(a)

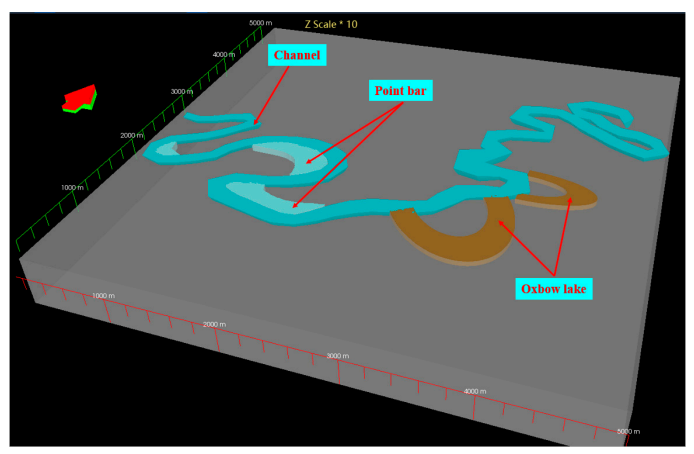

(b)

Figure 14. Modern meandering river image (a) and corresponding model by DMatlas (b).

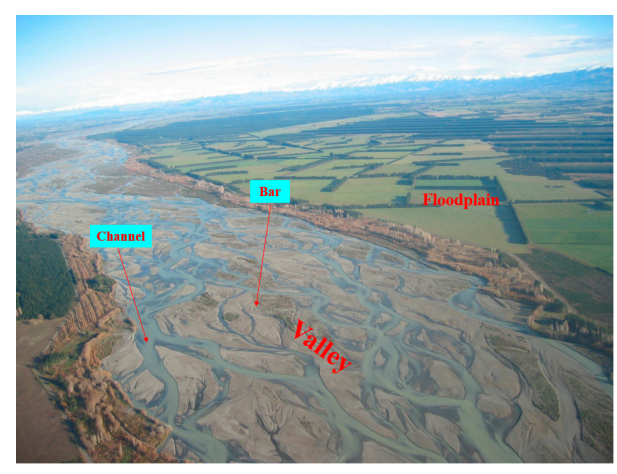

(a)

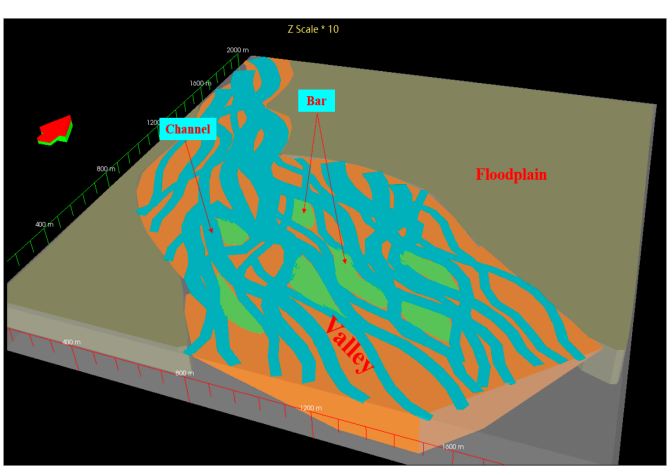

(b)

Figure 15. Modern braided river image (a) and corresponding model by DMatlas (b). 


\subsection{Delta Environment}

Modelers need to select the type of facies associations to be modelled first. Besides distributary channels and levee, point bar, bars, crevasse splay, inter-channel deposits, river mouth bar, distal sand bar, sheet sand, long-shore bar, tidal flat, sand-ridge, lagoon, flood plain, and pro-delta deposits are supported in a deltaic system. DMatlas also allows three belts modelling, namely delta plain, delta front and pro delta (Figure 16), which may be useful with scarce data or for quick pass situation.

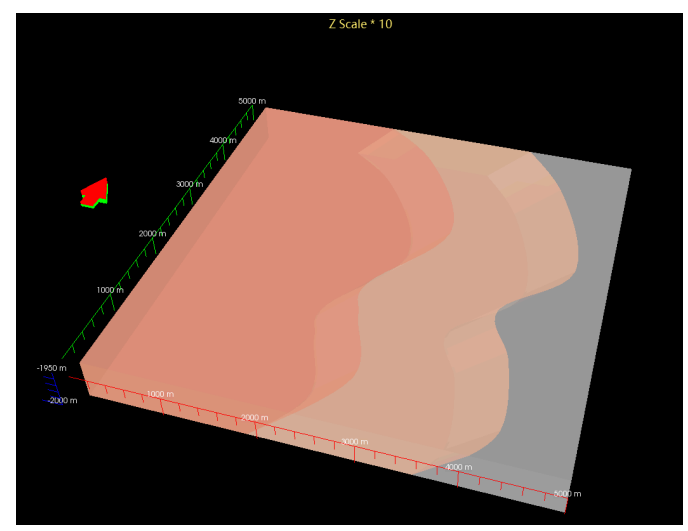

Figure 16. Three belts modelling of a delta system. From west to east: Delta plain, delta front, and pro delta.

Maximum vertical geometries are provided specifically to each facies association with geologic insights. For instance, for river mouth bars, only convex lenticular cross-section is provided. Figure 17 indicates a preliminary delta modelling referred to as the Mississippi River bird-foot [13], in which main distributary channels and proximal river mouth bars are modelled for demonstration.

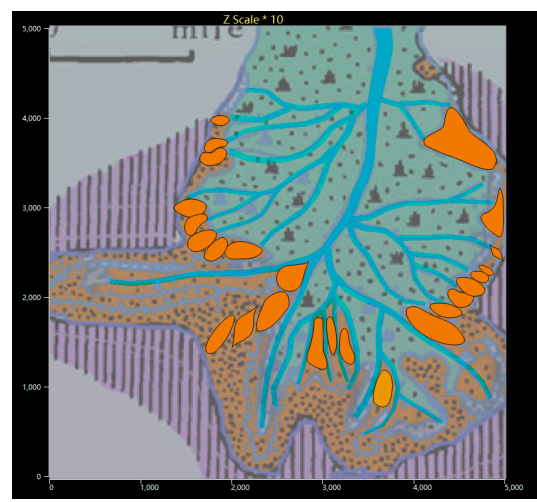

(a)

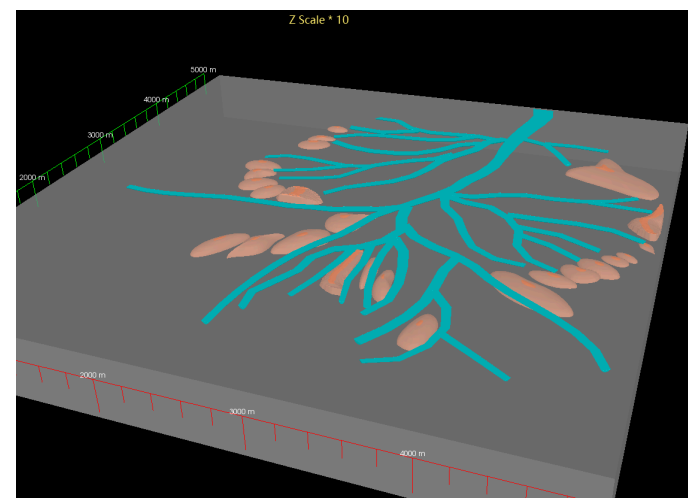

(b)

Figure 17. River-dominated delta model in prototype of the Mississippi River: (a) Plan view; (b) 3D view.

\subsection{Shallow Marine Carbonate}

Within the present functionalities of DMatlas, the carbonate environments are mainly focused on the shallow marine carbonates. Combining theories of Tucker [14], Wilson [15], and Read [16], DMatlas weakens concept of submarine topography and provides various carbonate reservoirs of different sedimentary origins, including carbonate tidal flat, ooid shoal, bioclastic shoal, and reef. Two depositional environments, carbonate ramp and platform, are available to aid users with modelling.

Figure 18 demonstrates a carbonate platform sediments concept modelled by DMatlas with tidal flat, patch reefs and linear reefs. Other facies, including carbonate tidal flat, ooid shoal, bioclastic shoal are also supported. 


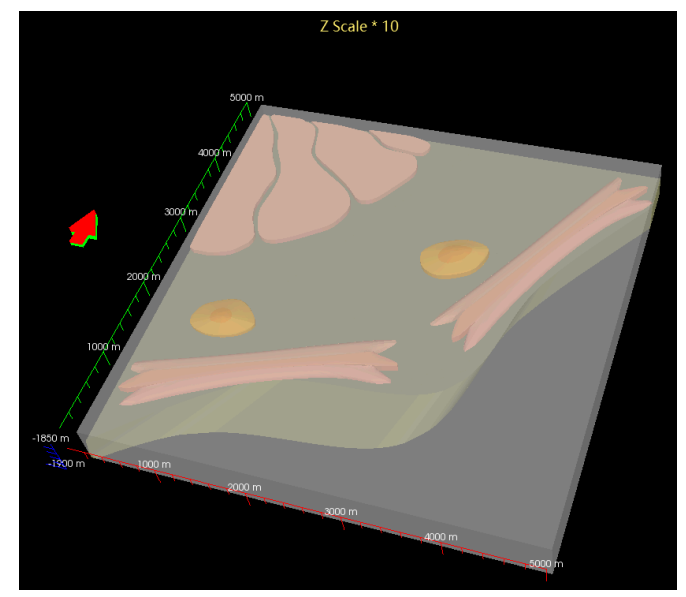

Figure 18. A simplified carbonate platform sediments concept model.

\subsection{Fault, Folds, and DFN}

A major difference between DMatlas modelling methodology and conventional geological modelling software is that sedimentary facies modelling could be carried on without a structural framework in place, and structural heterogeneities such as fault and folds could be captured later.

Taking fault modelling as an example. DMatlas supports modeling of dip-slip fault including normal fault and reverse fault, strike-slip fault and oblique-slip fault. Parameters defining a fault such as strike, dip direction, dip angle, and throw are provided by users, and a fault extending to edges horizontally and throughout the zone vertically will be generated. Figure 19a shows the fault modelling result of Wenmingzhai field in southern Bohai Basin, North China, which is a block-faulted lacustrine river-delta and fan-delta reservoir. Three NE-SW trending normal faults and two NW-SE trending faults are modeled based on top-Sha-3 structural interpretation (Figure 19b) [17].

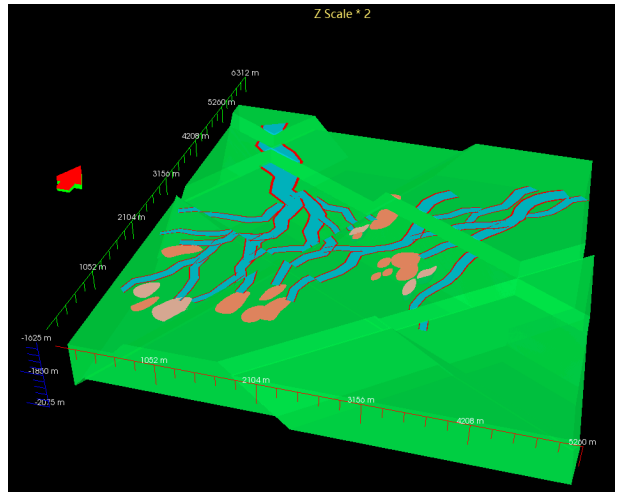

(a)

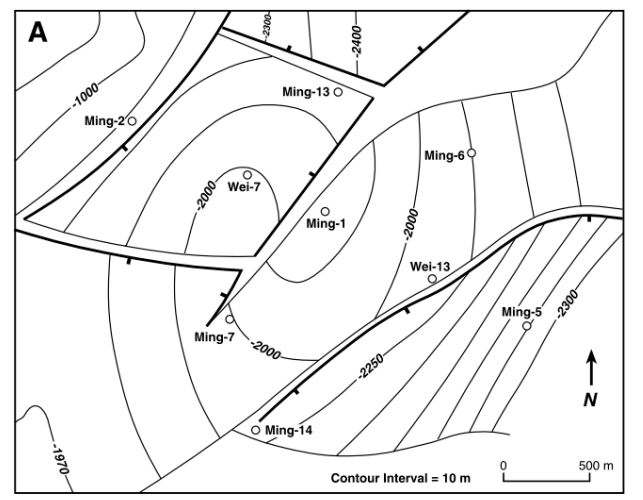

(b)

Figure 19. Top-Sha-3 fault modelling of Wenmingzhai field (a) referring to structural interpretation (b).

Fold modelling is similar to faults, achieved via geometry forward modelling: Anticline and syncline modellings are realized by simulating the occurrence of a fold's limbs and the axial plane; homoclines are modelled with inputs of dip direction and dip angle, as well as the anchor point coordinates.

DMatlas is good at delineating and characterizing fractures in terms of length, spatial organization, and vertical persistence. The types and scales of fractures, their geometry, and structural evolution could be conveniently kept and adjusted via fracture templates. Fractures in DMatlas are 2D plane surfaces whose starting depth and height are defined by users. Figure 20 demonstrates a prototype of fold related fractures posed by Price [18]. Three sets of fractures on a cylindrical anticline have been modelled. 


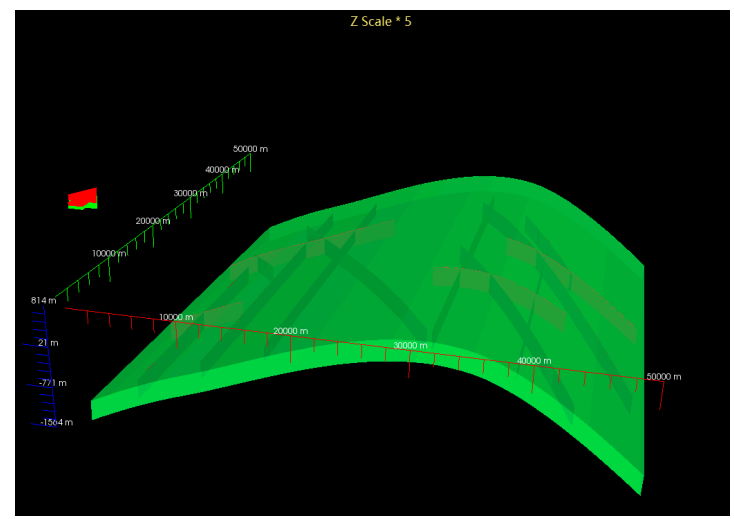

Figure 20. A prototype of fold related fractures modelled by DMatlas.

\subsection{Property Modelling}

Petrophysical modelling in DMatlas is similar to conventional modelling, which uses various statistical distributions to populate properties, but much more efficient since a lot of unnecessary reservoir details are spared.

The spatial distribution of petrophysical properties is greatly impacted by geologic heterogeneity, like the facies of discrete volumes modelled above in DMatlas. Petrophysical properties, including porosity and permeability, are distributed on a grid with a user-defined geostatistical distribution for each facies association. In DMatlas, hexahedron grids can be defined by users with $\mathrm{I} / \mathrm{J}$ and $\mathrm{K}$ direction numbers, of which the former two decides the $X / Y$ axis grid increment, the latter one decides the vertical division of the zone. Each grid is assigned with facies property which is defined in facies modelling. For each facies, a probability distribution of porosity is defined from experimental data. Linear relationship between logarithmic permeability and porosity is assumed to model permeability distribution within a facies. Parameters of slope and intercept can be adjusted according to experimental data.

Figure 21 shows I/J/K section view of porosity modelling result from the Member 8 of the Shihezi formation (P1h8) of partial Sulige Field in central Ordos Basin, North China [19-21], with a grid number $300 \times 300 \times 60$. Porosity has a normal distribution with average 0.12 , standard deviation 0.05 , and cut-off of $\min 0.07$ and max 0.22 . Permeability was modelled with a linear relationship with porosity, ranging from $0.5-20 \mathrm{mD}$ [22].
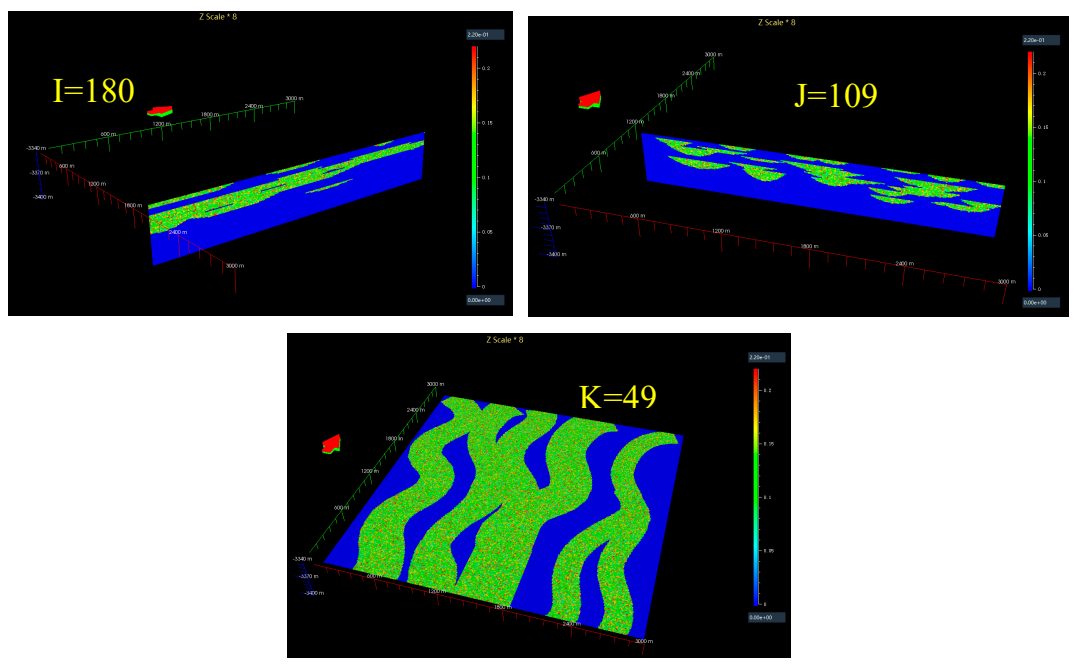

Figure 21. Porosity model of P1h8, Sulige Field, with sections along I/J/K. 


\subsection{Export of A Model}

DMatlas supports two types of files output for further study. One is under the "Property" module, exporting entire geocellular grids with property modelling results. Output formats intended for Eclipse [23] (Schlumberger, 2012), RESQML (V2.0, Energistics, Houston, The united states) [24,25] and DMatlas (self-defined for internal reservoir dynamic simulator) are available. Porosity model and permeability model could be exported separately.

The other output RESQML $2.0[24,25]$ is exporting DMatlas facies model as discrete volumes bounded by surfaces, which could be imported into conventional modelling software at any stage.

\section{Case Studies}

This section presents DMatlas' sketch-based interaction modelling process via a case study of Suizhong 36-1 Field (SZ 36-1 for short hereafter) and the North Oman fracture system. A full suite of stratigraphic, structural and petrophysical modelling demonstration is included.

\subsection{SZ 36-1 Field}

\subsubsection{Geologic Background}

The SZ 36-1 Field is located in Liaodong Bay, offshore Bohai Basin, NE China. It is a NESW Tertiary drape anticline lying on the SZ 36-1 structural belt along the central Liaoxi Rise (Figure 22). A major west-dipping normal fault (Liaoxi Fault) cuts the field into a western block and an eastern block. The eastern block is a NE-trending half-anticline measuring $13 \mathrm{~km}$ long by $4.3 \mathrm{~km}$ wide with flanks dipping at $6-10^{\circ}[26]$, which is the main modelling area of this work. In the eastern block, the oil water contact (OWC) varies between the various reservoir units due to the presence of shale barriers.
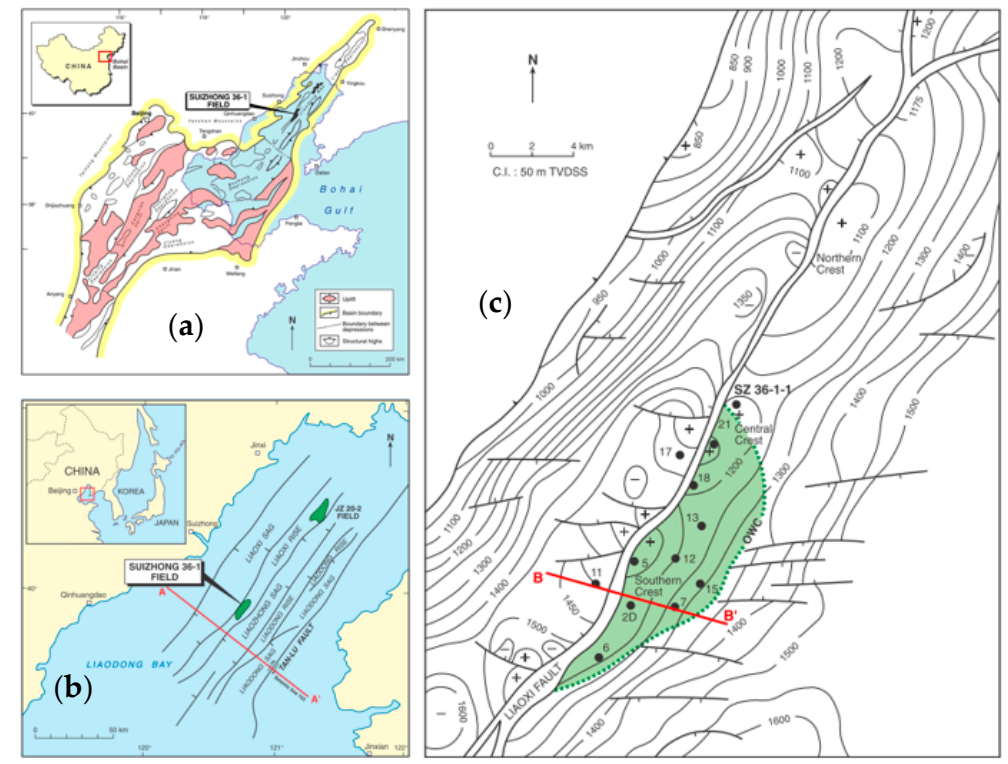

Figure 22. (a) Map showing location of the SZ 36-1 field and major structural subdivisions of the Bohai Basin [27]. The Liaodong Bay Depression, in which the Suizhong 36-1 is located, is the offshore extension of the onshore Liaohe Depression. (b) Map showing location of the SZ 36-1 field within the regional tectonic framework of Liaodong Bay [28] (c) Top Dongying Formation structural contour map showing the SZ 36-1 structural belt cut by the major Liaoxi Fault and the oil-bearing (the modeled) area [27]. Also shown is the location of cross-section B-B' in Figure 23.

Oil in the SZ 36-1 Field is mainly contained in the middle section of the lower Dongying Formation, in a series of stacked, river-dominated lacustrine delta lobes. The lower Dongying Formation, up to $3000 \mathrm{~m}$ thick, is dominated by shallow to deep lacustrine shales intercalated with deltaic and sub 
lacustrine-fan sandstones (Figure 23). The most important sand-bodies are distributary channels and mouth bars [27].

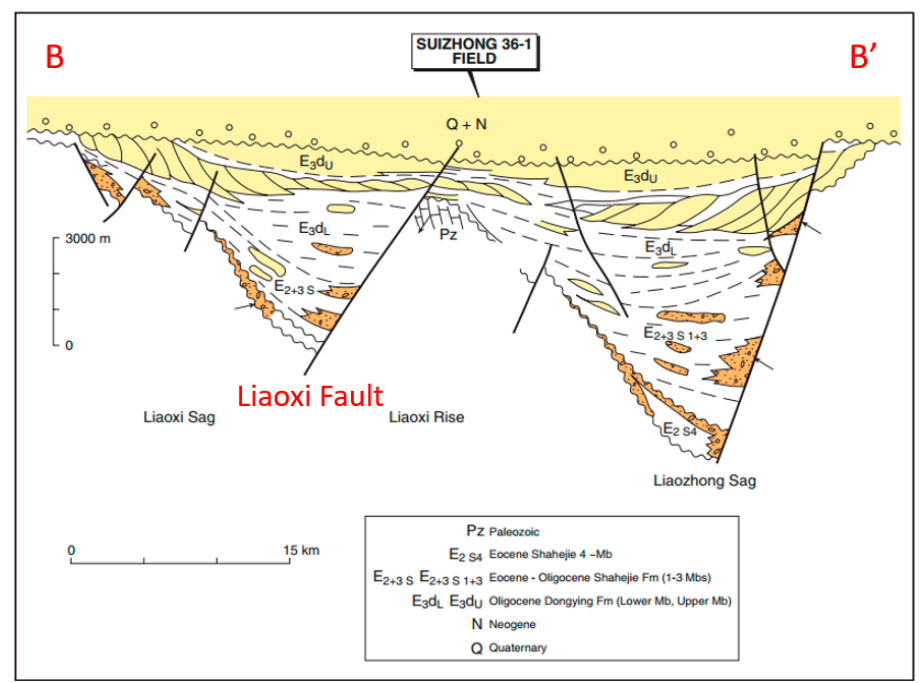

Figure 23. Schematic NW-SE cross-section illustrating evolution of depositional systems in the Liaoxi and Liaozhong sags [27].

The Upper Oligocene lower Dongying Formation is divided into two sections, overlapping the weathered basement high and the Shahejie Formation in the depression, which is an important source rock in the basin. The Miocene Guantao Formation overlies the Dongying Formation unconformably, which was deposited in a fluvial environment providing a minor reservoir to the field (Figure 24).

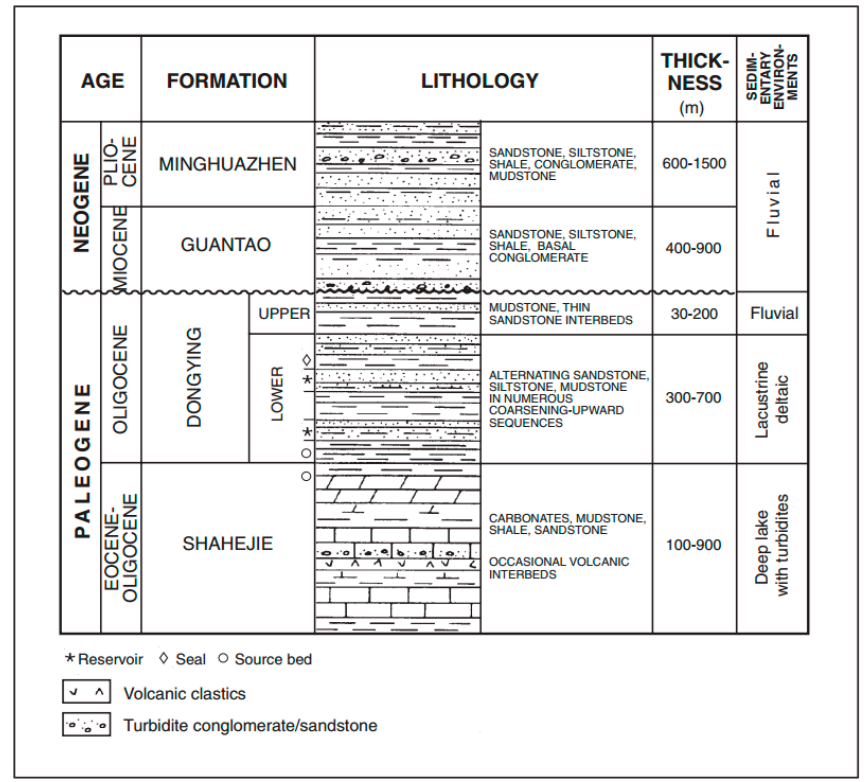

Figure 24. Stratigraphy of the Liaodong Bay Depression indication source, reservoir and seal beds [29].

The reservoir sandstones in SZ36-1 Field exhibit good reservoir properties for the sake of their poor consolidation and moderate burial depth $(1327-1960 \mathrm{~m})$, with porosity range of $26 \%-36 \%$ (average 32\%) [26,30]. Air permeability ranges 100-18000 mD and averages $2600 \mathrm{mD}$. Porosity and permeability in the upper section of Unit I are $29 \%-35 \%$ (average $31.9 \%$ ) and $400-10,000 \mathrm{mD}$ (average $3056 \mathrm{mD}$ ) respectively. 


\subsubsection{Facies Modelling}

Based on the above deposition concepts and reservoir statistical analysis, the project width/length are both set as 14km, with the top depth of the Lower Dongying formation $-1175 \mathrm{~m}$ and base $-1605 \mathrm{~m}$ [31].

The lower Dongying Formation reservoir is divided into Unit 0, I, II, and III from top to base (Figure 25), of which the main reservoir unit (Unit I) is modelled in this demo project. Guided by theories of sequence stratigraphy and hierarchical reservoir architecture [12], individual river mouth bar and distributary channel (4th order) was placed to different depths and united together to form a 5th order delta lobe. Different periods of lobes placed in different plane and vertical positions form a progradation delta system.

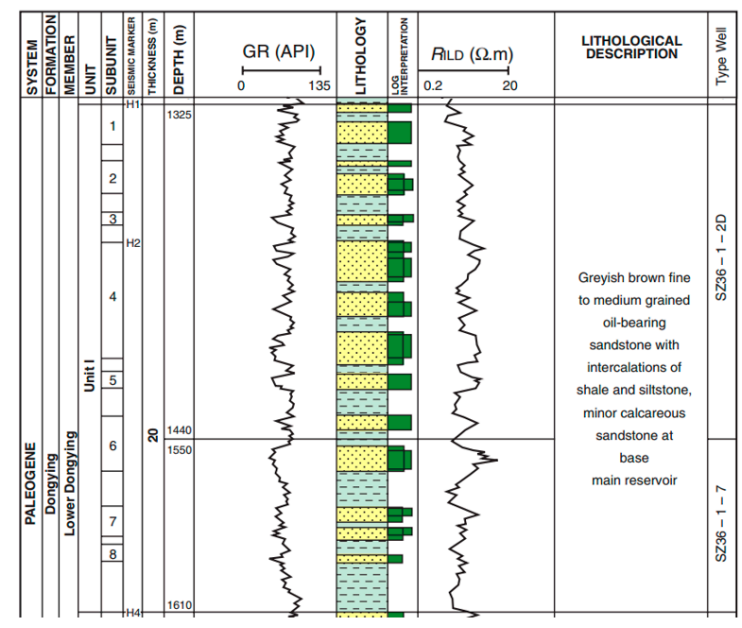

Figure 25. Composite log showing reservoir zonation in lower Dongying Formation, SZ 36-1 Field [31].

Then, the specification of the selected object is gathered. The facies modeling proceeds by randomly choosing the parameters' value from the predefined distribution, like the sand scale and content percentage summarized from public literature and outcrop analysis (Table 1).

Table 1. Sand scale, form and interbed content percentage of different sedimentary facies associations in SZ 36-1 oilfield.

\begin{tabular}{cccccc}
\hline \multirow{2}{*}{ Facies Association Type } & \multicolumn{3}{c}{ Sandbody Scale/m } & Sandbody Shape & $\begin{array}{c}\text { Average Percentage of } \\
\text { Interbed Thickness/\% }\end{array}$ \\
\cline { 2 - 5 } & Vertical Scale & Length & Wlane Scale & & Bidth \\
\hline $\begin{array}{c}\text { Subaqueous } \\
\text { distributary channel }\end{array}$ & $3.0-12.5$ & $1000-4000$ & $200-600$ & & $\begin{array}{c}\text { Belted overlapped } \\
\text { and connected } \\
\text { River mouth bar }\end{array}$ \\
$\begin{array}{c}\text { Sheet sand } \\
\text { Overbank }\end{array}$ & $2.0-6.5$ & $500-800$ & $300-500$ & $\begin{array}{c}\text { Potato-like overlapped } \\
\text { and connected } \\
\text { Sheet-like } \\
\text { Fan-shaped }\end{array}$ & 15 \\
\hline
\end{tabular}

The object is placed in the model randomly or by following geologic rules, Soft data, such as aerial image, isopach maps, and sedimentary facies map, are used as references to aid facies layout. By defining individual mouth bar's plane geometry and maximum cross-section, sand-bodies are modelled in place (Figure 26). 


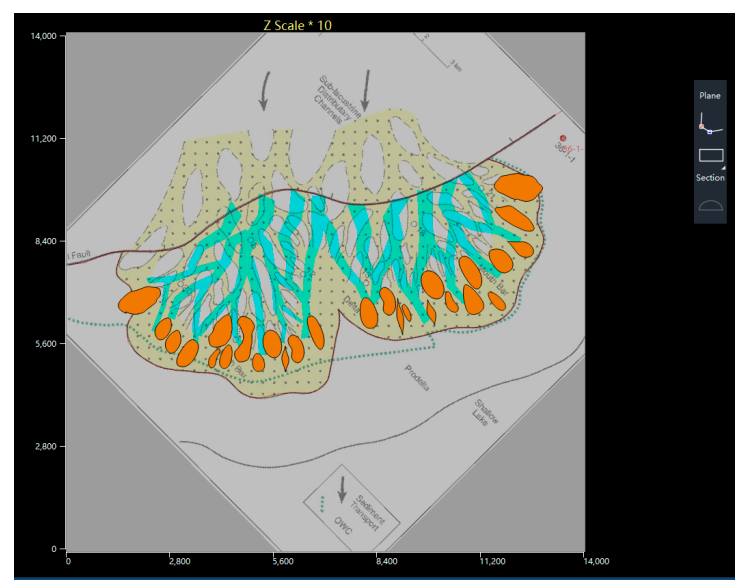

Figure 26. Sketch of the distributary channels and river mouth bars of Unit I with reference map.

Facies distribution sectioned at one sand-body's top surface (Figure 27a) could be easily checked afterwards, as well as reservoir vertical architecture (Figure 27b).

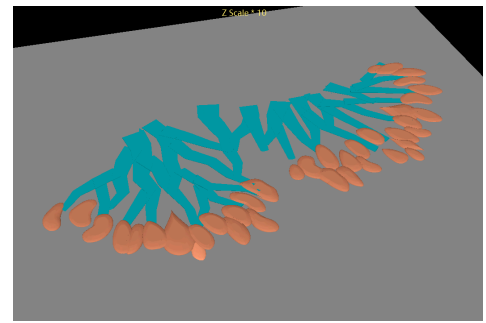

(a)

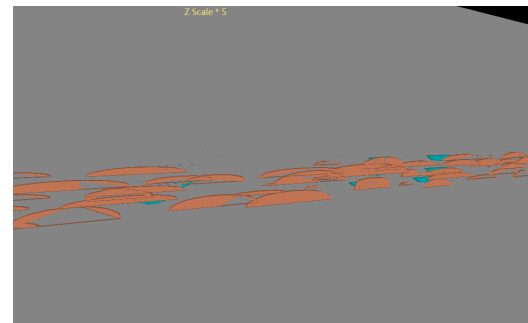

(b)

Figure 27. Facies modelling of Unit I, Lower Donging Formation, SZ 36-1: (a) Top view at one sand-body's top surface; (b) cross-section view of river mouth bars along N-S direction.

There is a tool to estimate whether the thickness or other geometry parameters match the statistics. Take the river mouth bar deposited at the depth of $1325 \mathrm{~m}$ TVDSS (True Vertical Depth SubSea) as an example, statistical result is as shown in Figure 28.

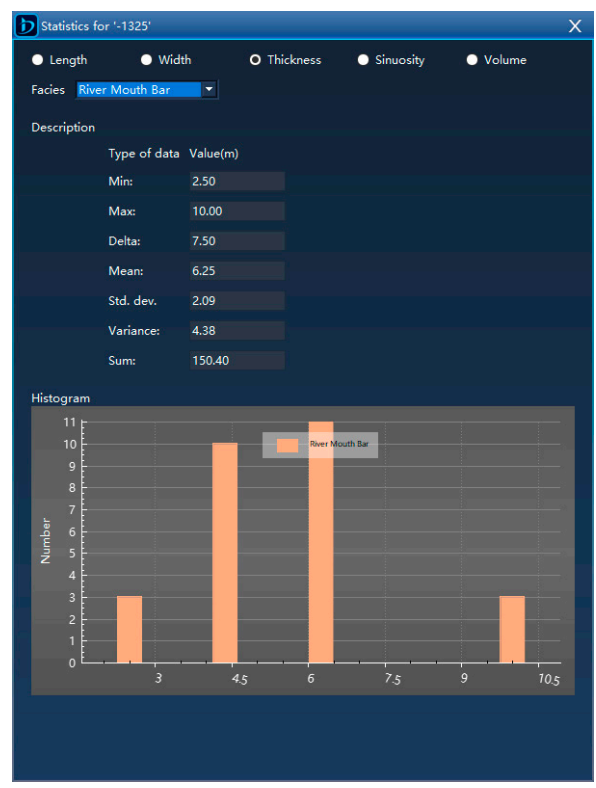

Figure 28. Statistical result of river mouth bars at $1325 \mathrm{~m}$ TVDSS. 
Histogram shows that the number of sandbars with thickness 4-6 $\mathrm{m}$ far exceed that of others, and the average thickness is $6.25 \mathrm{~m}$, which is reasonable according to reservoir characterization and could be counted as a high case since the average thickness $6.25 \mathrm{~m}$ is close to the maximum thickness. Middle and low case could be fast realized by replicating the project and change the sandbodies' geometry. If there are more detailed petrophysical interpretations available, users could adjust geometry parameters to further prototype reservoir deposition concepts.

\subsubsection{Variable Thickness}

Users always have a choice to keep the zone of uniform thickness to rapidly test a range of possible geological concepts. If the model is expected to be used for reservoir simulations, it is important to model tectonic deformation like variable thickness, fault, folding, or other vital heterogeneity like fractures.

On a field-wide scale, the gross reservoir thickness generally varies between $200 \mathrm{~m}$ and $400 \mathrm{~m}$ [32]. Referring to top Dongying Formation structural contour map [27], Lower Dongying formation could be deformed close to real topography as Figure 29, showing alternating sag and rise.

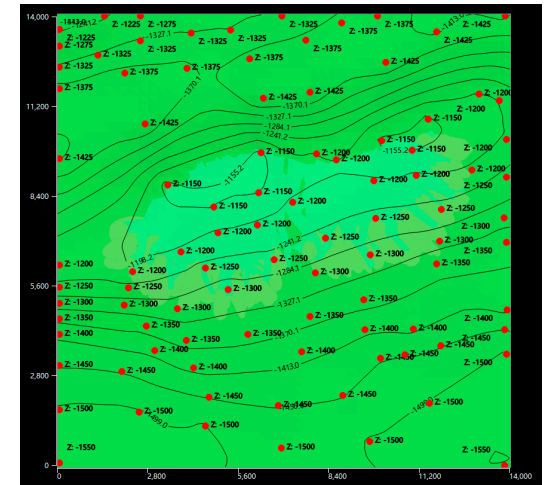

(a)

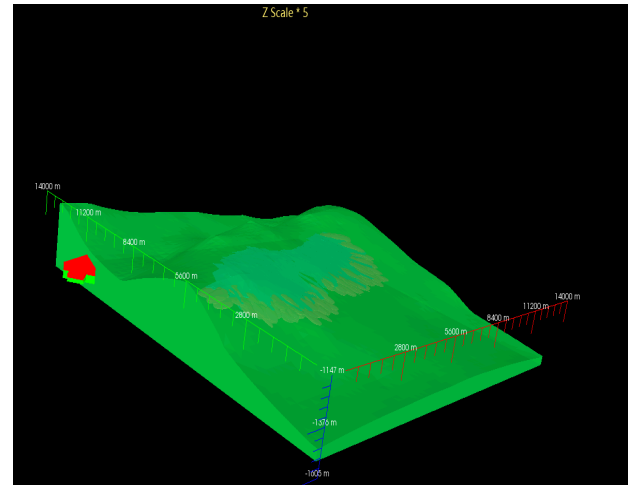

(b)

Figure 29. (a) Depth controlling points and resulting contours used to deform the formation; (b) Lower Dongying formation with variable thickness in 3D (Z Scale: 5).

\subsubsection{Liaoxi Fault}

Liaoxi Fault as the major west-dipping normal fault cuts the field into a western block and an eastern block. By estimating and defining the elements of the fault attitude, a faulted formation could be modelled as Figure 30 shown.

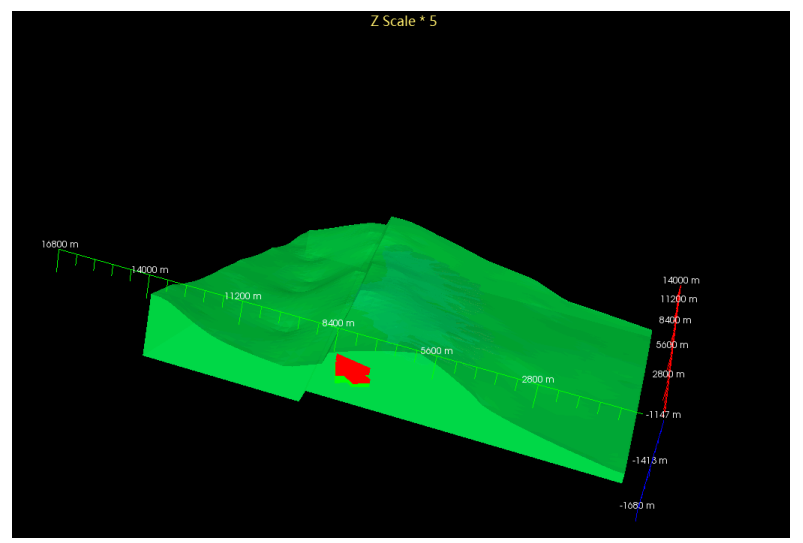

Figure 30. Faulted Lower Dongying Formation (Fault strike: $80^{\circ}$, Dip direction: $170^{\circ}$, Dip angle: $30^{\circ}$, Throw: $75 \mathrm{~m}$ ). 


\subsubsection{Petrophysical Properties Modelling}

The grid number was set to $200 \times 200 \times 430$ in this context of $14000 \mathrm{~m} \times 14000 \mathrm{~m} \times 430 \mathrm{~m}$ project size. For sub-units 1 and 2, Unit I in Lower Dongying Formation, porosity of Normal distribution with average 0.32 , standard deviation 0.125 , and cut-off 0.29 and 0.35 are modelled, while permeability modelling adopts experienced linear relationship with porosity: $\log _{\mathrm{K}}=23.59 \times$ Por -4.5 .

After gridding and properties population by assigning certain statistical distribution, a porosity model of SZ 36-1 field and intersections along K direction are modelled and shown in Figure 31.
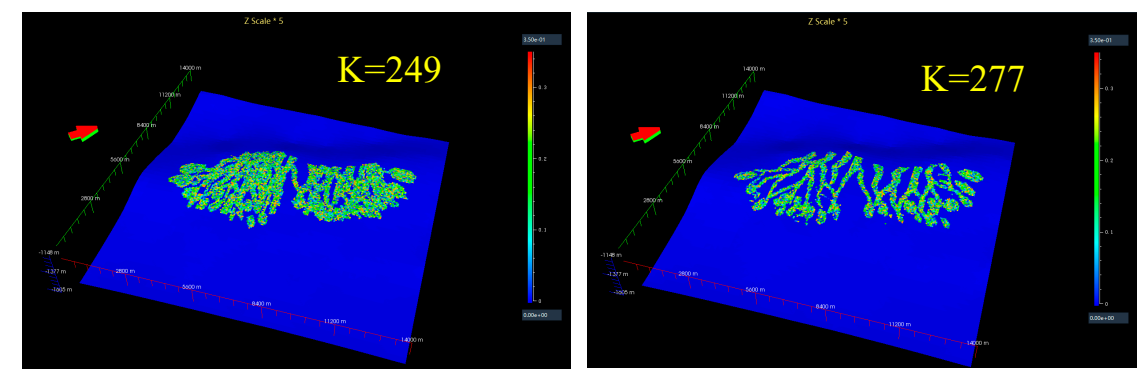

Figure 31. Intersection along K direction of Porosity model for SZ 36-1 Field.

\subsubsection{Volume Calculation Result from Dmatlas}

With $\mathrm{N} / \mathrm{G}=0.4, \mathrm{Sw}=0.2$, Boi $=1.15$ and the porosity model, DMaltas has a volume calculation of 7.14E7 sm $\mathrm{sm}^{3}$ for the sub-units 1 and 2, Unit I in SZ 36-1 field. The grid could be exported as Eclipse format and imported into Petrel, whose volume calculation result with the same grid, property model and other parameters is $7.2 \mathrm{E} 7 \mathrm{sm}^{3}$ STOIIP.

\subsection{The North Oman Fracture System}

\subsubsection{Geologic Background of the Natih Formation, Jebel Madmar}

Jebel Madmar is one of the well-preserved anticlines related to thrust faults near the Salakh Arch, Oman Foothills, which exposes the platform carbonates of Cretaceous Natih Formation with local underlying Nahr Umr shale (Figure 32). Its structure and mechanical stratigraphy have been studied through integration of high-resolution satellite analysis, outcrop characterization and geochemical laboratory study by workers from Montpellier University (2003) and PDO development team (2003-2004) [33]. Three dominant sets of structures in Madmar, NE- and NW-trending fractures and fractures corridors, and WNW-trending normal faults were recognized [33], which are formed prior to development of Madmar anticline. NE and NW fractures comprise a multi-scaled, nested system of strata-bound fractures and fracture corridors. 3D echelon fractures arrangements and parallel overlapping fracture configurations are common for the NE fractures.

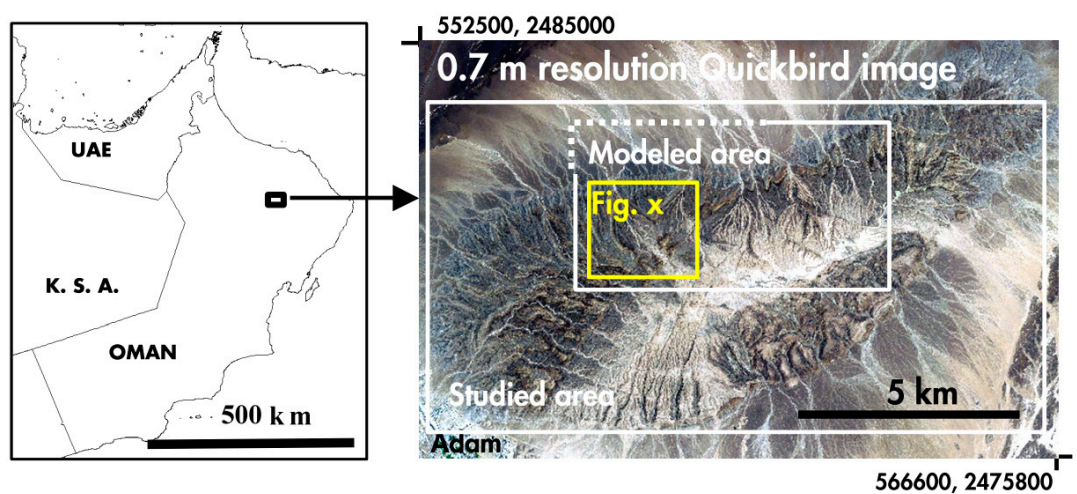

Figure 32. Location of Jebel Madmar in North Oman [34]. 
Mechanical stratification at various scales with a nested hierarchy of fractures at high-angle to layering in the Natih Formation in Madmar have also been achieved.

The gross thickness of the Natih platform carbonates is about $300 \mathrm{~m}$. It is traditionally subdivided into seven members (named Natih-A to -G from top to base) [35], which are mainly composed of bioclastic packstone and marls.

\subsubsection{Fractures Modelled by DMatlas}

A series of templates that capture structural geological heterogeneity at the inter-well scale and integrated understanding of the geometry and evolution of the Madmar fracture system are established (Figure 33). These templates have $500 \times 500 \mathrm{~m}$ fracture map patterns which could be combined in a discrete fracture model with great freedom of re-scaling.
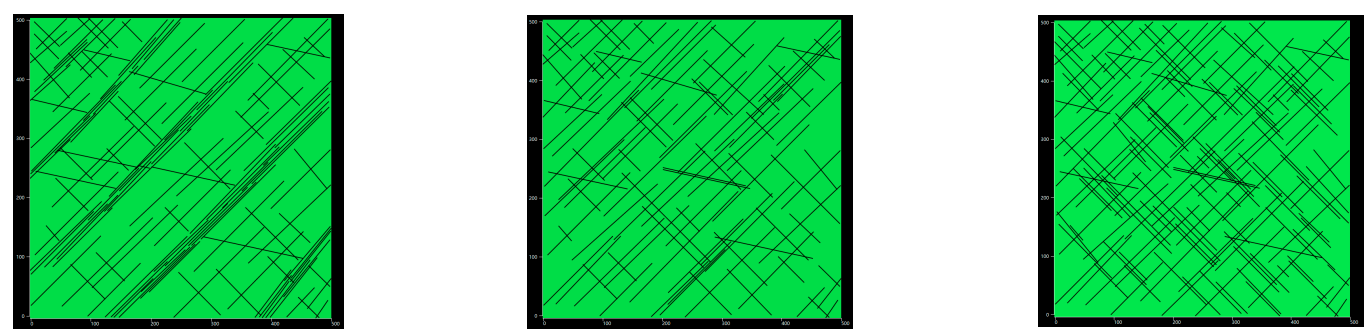

Figure 33. Fracture map patterns indicating NE, NW, and WNW sets for Natih E.

The fracture model is characteristic of:

- A sector scale of $6000 \times 6000 \mathrm{~m}$ area on the back-limb of Madmar anticline.

- Made up of the sets that dominate subsurface structure in the region at the well- and inter-well scales: WNW normal faults, NW fractures, and NE regional fractures, as well as subordinate northerly trending structures.

- 11 upscaled main mechanical stratigraphy are established in total for Natih E.

- Fractures and corridors with vertical dips.

- Fracture width, fault throw and other structures (e.g., low-angle thrusts) are not in the model.

Vertical persistence of fracture templates could be separately adjusted to fit hierarchical mechanical layering. Figure 34 shows the nested hierarchy of fractures at high-angle to layering in the Natih Formation. The relationships between fracturing and layering exhibits strong variation of mechanical properties. With assessment of regional consistency and evolution, detailed surface-subsurface comparison and integration, links between the fracture model of Jebel Madmar and that of other fields within a regionally consistent structural framework could be built. 


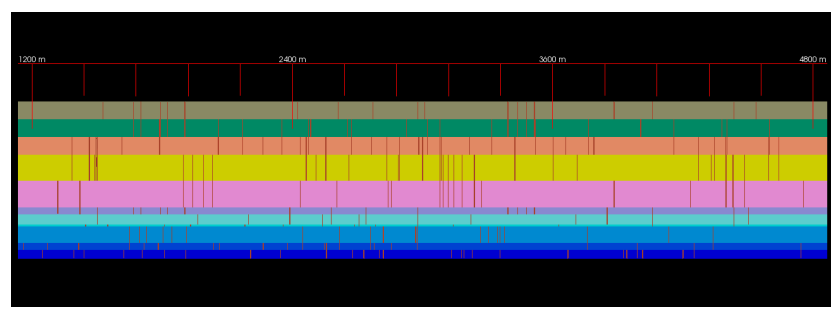

(a)

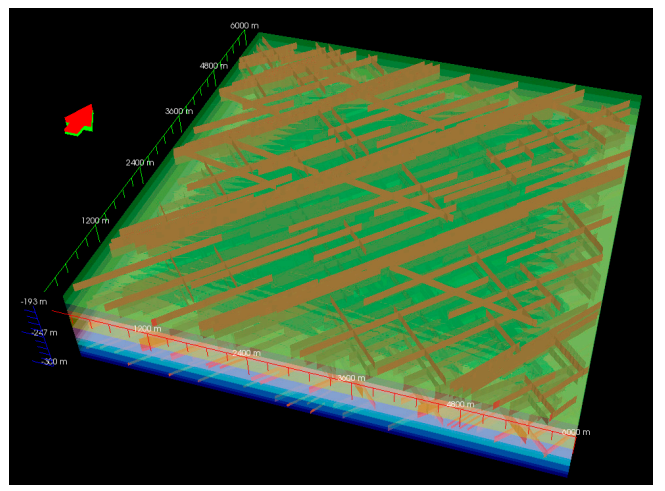

(b)

Figure 34. Cross-section of the fracture model for the Natih E, Jebel Madmar in North Oman (Z scale:10):

(a) View to North; (b) Oblique 3D view.

\section{Conclusions}

Geological modelling is key to understanding of the target reservoir and designing an optimal recovery scheme. The conventional way of geological modelling is mainly based on the "hard data". However, there are not enough sufficient "hard data" available to build a reasonable model in some cases, such as in early stage of oil recovery and $\mathrm{CO}_{2}$ geological storage in saline aquifers with limited "hard data" for a big scale area field [36,37]. In EOR projects, we need to understand the heterogeneity of reservoir properties in inter-well scale. In conventional way of geological modelling, it usually takes a long time to build a model. Moreover, the model cannot be reused by different phases of a project or by different users. There is also much room to improve the time efficiency of the modelling.

To address this problem, this work proposes a new knowledge driven methodology of geological modelling and has developed a new geological modelling software DMatlas accordingly. In the framework of the new methodology, (1) conceptual models can be constructed according to different depositional environments with the help of "soft data" such as outcrop, public literature, related maps and geologists' own understandings without reference to a predefined gridding block; (2) the basic structures of faults, folds and DFN can be created by user definitions of the main features; (3) models can be stored on server linked with DMatlas and reused by different users via keyword search; (4) property models can be constructed with hexahedron gridding scheme populated by statistical distributions of porosity and relationship function of porosity and permeability within each different facies; (5) DMatlas models can be exported in various formats such as Eclipse text file and RESQML 2.0.

To show the workflow of DMatlas, cases studies of SZ 36-1 field in Bohai basin, China and Jebel Madmar, Oman are presented. In SZ 36-1 case, modelling of facies (delta environment), fault, properties and reserve volume calculations are discussed in detail. The case demonstrates that 3D models of common geologic features can be created rapidly and intuitively using a grid-free object-based method. The Madmar modelling case shows complex facture systems which can be modelled by DMatlas based on "soft data".

The existing models from the DMatlas model library, especially typical concepts and case models of fluvial and deltaic systems have made it possible to quickly build modeler's own model. For current 
version, only the stochastically generation of channels are available. When modeling sandbodies other than channels, the hand-free modeling method is sometimes time-consuming, taking days to build hundreds of meters- thick reservoirs. DMatlas is now developing stochastically generation of many facies or facies associations, following user-defined distribution with or without well-data conditioning, which will further improve modeling efficiency and better comply with statistics analysis result.

Author Contributions: Investigation, X.Z.; Methodology, J.L.; Software, B.L.; Validation, Q.Z.; Writing一original draft, J.L. and X.Z.; Writing-review \& editing, R.A.

Funding: National Key R\&D Program of China (Grant No. 2016YFE0102500).

Acknowledgments: Thanks for the fully support of Dimue Technology Limited Company and permission to publish this work, and also thanks for the constructive suggestions and comments from two anonymous reviewers.

Conflicts of Interest: The authors declare no conflict of interest.

\section{References}

1. Fanchi, J.R. Chapter 2-Geological modeling. In Principles of Applied Reservoir Simulation, 4th ed.; Fanchi, J.R., Ed.; Gulf Professional Publishing: Houston, TX, USA, 2018; pp. 9-33.

2. Howell, J.A.; Martinius, A.W.; Good, T.R. The application of outcrop analogues in geological modelling: A review, present status and future outlook. Geol. Soc. Lond. Spec. Publ. 2014, 387, 1-25. [CrossRef]

3. Schlumberger. Petrel Structural Modeling Training and Exercise Guide; Schlumberger: Houston, TX, USA, 2014.

4. Li, J.; Li, X. Analysis of u-tube sampling data based on modeling of $\mathrm{CO} 2$ injection into $\mathrm{CH} 4$ saturated aquifers. Greenh. Gases Sci. Technol. 2015, 5, 152-168. [CrossRef]

5. Sech, R.P.; Jackson, M.D.; Hampson, G.J. Three-dimensional modeling of a shoreface-shelf parasequence reservoir analog: Part 1. Surface-based modeling to capture high-resolution facies architecture. AAPG Bull. 2009, 93, 1155-1181. [CrossRef]

6. Deveugle, P.E.K.; Jackson, M.D.; Hampson, G.J.; Stewart, J.; Clough, M.D.; Ehighebolo, T.; Farrell, M.E.; Calvert, C.S.; Miller, J.K. A comparative study of reservoir modeling techniques and their impact on predicted performance of fluvial-dominated deltaic reservoirs comparison of reservoir modeling techniques. AAPG Bull. 2014, 98, 729-763. [CrossRef]

7. Li, S.; Zhang, Y.; Ma, Y.Z.; Dorion, C.; Daly, C.; Zhang, T. A comparative study of reservoir modeling techniques and their impact on predicted performance of fluvial-dominated deltaic reservoirs: Discussion. AAPG Bull. 2018, 102, 1659-1663. [CrossRef]

8. Perrin, M.; Zhu, B.T.; Rainaud, J.F.; Schneider, S. Knowledge-driven applications for geological modeling. J. Pet. Sci. Eng. 2005, 47, 89-104. [CrossRef]

9. Mehran, M.H.; Michael, J.P.; Clayton, V.D. Improved geostatistical models of inclined heterolithic strata for McMurray Formation, Alberta, Canada. AAPG Bull. 2013, 97, 1209-1224.

10. Crama, Y.; Hammer, P.L. Boolean Functions: Theory, Algorithms, and Applications; Cambridge University Press: Cambridge, UK, 2011.

11. Ferguson, R.S. Practical Algorithms for 3d Computer Graphics, 3nd ed.; Routledge: Abingdon, UK, 2014.

12. Miall, A.D. Reconstructing the architecture and sequence stratigraphy of the preserved fluvial record as a tool for reservoir development: A reality check. AAPG Bull. 2006, 90, 989-1002. [CrossRef]

13. Fisher, W.L.; Brown, L.F., Jr.; Scott, A.J.; McGowen, J.H. Delta Systems in the Exploration for Oil and Gas; The University of Texas at Austin, Bureau of Economic Geology: Austin, TX, USA, 1969; p. 212.

14. Tucker, M.E. Shallow-marine carbonate facies and facies models. Geol. Soc. Lond. Spec. Publ. 1985, 18, 147-169. [CrossRef]

15. Wilson, J.L. Carbonate Facies in Geologic History; Springer: New York, NY, USA, 1975.

16. Read, J.F. Carbonate platform facies models. AAPG Bull. 1985, 69, 1-21.

17. Li, Y. The Highly Faulted Oilfield in Wenmingzhai; Petroleum Industry Press: Beijing, China, 1997; p. 140.

18. Price, N.J. Fault and Joint Development in Brittle and Semi-Brittle Rock; Pergamon, Turkey, 1966; p. 186.

19. Yang, H.; Fu, J.; Wei, X.; Liu, X. Sulige field in the Ordos basin: Geological setting, field discovery and tight gas reservoirs. Mar. Pet. Geol. 2008, 25, 387-400. [CrossRef]

20. Guo, J.L. Study on Relatively Prolific Reservoir Distribution of Sulige Gasfield; China University of Geosciences: Wuhan, China, 2008. 
21. Ran, X.Q.; Li, A.Q. Sulige Gas Development Approach; Petroleum Industry Publishing: Beijing, China, 2008 ; p. 246.

22. Zhu, X.; Liu, C. Identification of effective upper paleozoic reservoirs in Sulige area. Nat. Gas Ind. 2006, 26, 1-3.

23. Schlumberger. Eclipse Reservoir Simulation Software; Schlumberger: Houston, TX, USA, 2012.

24. King, M.J.; Ballin, P.R.; Bennis, C.; Heath, D.E.; Hiebert, A.D.; McKenzie, W.; Rainaud, J.-F.; Schey, J. Reservoir modeling: From rescue to RESQML. SPE Reserv. Eval. Eng. 2012, 15, 127-138. [CrossRef]

25. Verney, P.; Gautreau, C.; Rainaud, J.-F.; Deny, L.; Magsipok, J.; Marcotte, D. RESQML version 2 uses new technologies to improve data exchange for subsurface modeling processes. In SPE Intelligent Energy Conference $\mathcal{E}$ Exhibition; Society of Petroleum Engineers: Utrecht, The Netherlands, 2014; p. 11. [CrossRef]

26. Xin, S.G.; Li, Y.Q.; Ding, K.W. Exploration Practice in Major Oilfields of China; Petroleum Industry Press: Beijing, China, 2002.

27. Xin, S.G.; Hao, F.G.; Li, Y.Q.; Ding, K.W. Major Non-Marine Oil Fields of China; Petroleum Industry Press: Beijing, China, 1997.

28. Xin, S.G.; Luedke, D.K. Field development of the Suizhong 36-1 oil field using geophysics and reservoir simulation. SEAPEX Proc. 1990, 9, 121-132.

29. Gustavson, J.B.; Xin, S.G. The Suizhong 36-1 oil field, Bohai Gulf, offshore China. AAPG Memoir. 1992, 54, 459-470.

30. Deng, M.Y.; Zhang, C.Y.; Dong, X.L.; Liu, Z.M.; Liu, Q.H. Evaluation on formation damage by well operation fluid in SZ 36-1 oil field. China Offshore Oil Gas Eng. 2001, 13, 17-24. [CrossRef]

31. Zhu, X.; Dong, Y.; Yang, J.; Zhang, Q.; Li, D.; Xu, C.; Yu, S. Sequence stratigraphic framework and distribution of depositional systems for the paleogene in Liaodong bay area. Sci. China Ser. D Earth Sci. 2008, 51, 1-10. [CrossRef]

32. Dai, H.D.; Gong, Z.S. The Development of Offshore Oil-Gas Fields in China; Petroleum Industry Press: Beijing, China, 2003; p. 281.

33. Bazalgette, L. Relations plissement/fracturation multi échelle dans les multicouches sédimentaires du domaine élastique/fragile: Accommodation discontinue de la courbure par la fracturation de petite échelle et par les articulations. In Possibles Implications Dynamiques dans les Écoulements des Reservoirs; Université Montpellier II-Sciences et Techniques du Languedoc: Montpellier, France, 2004.

34. De Keijzer, M.; Hillgartner, H.; Al Dhahab, S.; Rawnsley, K. A surface-subsurface study of reservoir-scale fracture heterogeneities in cretaceous carbonates, north Oman. In Fractured Reservoirs; Lonergan, L., Jolly, R.J.H., Rawnsley, K., Sanderson, D.J., Eds.; Geological Society of London: London, UK, 2007. [CrossRef]

35. Tschopp, R.H. Development of the fahud field. In 7th World Petroleum Congress; World Petroleum Congress: Mexico City, Mexico, 1967; p. 8.

36. Lei, H.; Li, J.; Li, X.; Jiang, Z. Numerical modeling of co-injection of N2 and O2 with CO2 into aquifers at the Tongliao CCS site. Int. J. Greenhouse Gas Control 2016, 54, 228-241. [CrossRef]

37. Ahmed, R.; Li, J. A numerical framework for two-phase flow of CO2 injection into the fractured water-saturated reservoirs. Adv. Water Resour. 2019, 130, 283-299. [CrossRef]

(C) 2019 by the authors. Licensee MDPI, Basel, Switzerland. This article is an open access article distributed under the terms and conditions of the Creative Commons Attribution (CC BY) license (http://creativecommons.org/licenses/by/4.0/). 